\title{
Awareness About Mother-To-Child Transmission of HIV Infection Among Women in Nigeria
}

\author{
Samson Ayo Deji ${ }^{1, *}$, Olusola Odu ${ }^{1}$, Olayinka Olasode ${ }^{2}$ \\ ${ }^{1}$ Department of Epidemiology and Community Health, College of Medicine, Ekiti State University, Ado Ekiti, Nigeria \\ ${ }^{2}$ Department of Dermatology, College of Health Sciences, Obafemi Awolowo University, Ile Ife, Nigeria
}

Email address:

samdeji3@hotmail.com (S. A. Deji)

To cite this article:

Samson Ayo Deji, Olusola Odu, Olayinka Olasode. Awareness About Mother-To-Child Transmission of HIV Infection Among Women in Nigeria. Journal of Family Medicine and Health Care. Vol. 2, No. 4, 2016, pp. 89-94. doi: 10.11648/j.jfmhc.20160204.20

Received: October 14, 2016; Accepted: October 29, 2016; Published: November 30, 2016

\begin{abstract}
The concerns of children testing positive to HIV virus shortly after birth is alarming in developing countries. The study assessed the level of awareness of women about Mother To Child Transmission. (MTCT) in Nigeria. The study used secondary data from the National Demographic and Health Survey (NDHS) conducted in the six geopolitical zones of Nigeria. The National Demographic Health Survey is one of the most comprehensive Nigerian datasets that contains extensive information on the reproductive health of women between ages 15-49 years and therefore provides a unique opportunity to study the knowledge of women in the reproductive age group in the country. The 2008 Nigerian NDHS survey sample was made up of 33,385 women of reproductive age group from the six geopolitical zones. The data set was obtained from already analyzed results of the NDHS 2008. The results were summarized into tables and charts using Microsoft excel. Most women interviewed for the study were from the north west zone (24\%) out of the six geopolitical zones in Nigeria. Twelve percent of the respondents were from the south east zone. Respondents from the south east zone reported highest awareness about the fact that HIV could be transmitted through breastfeeding to the child, $(70.1 \%)$, while respondents from north west demonstrated least awareness that HIV could be transmitted through breastfeeding to the child. About $51.5 \%$ of pregnant women among the respondents reported adequate knowledge that HIV could be transmitted by breastfeeding while $28.6 \%$ were aware that the risk of MTCT could be reduced through the use of anti-retroviral drugs and $26.1 \%$ were aware that HIV could be transmitted by breastfeeding and the risk of MTCT could be reduced by taking anti-retroviral drugs. Most women do not have adequate awareness of mother to child transmission of HIV in the six geopolitical zones of Nigeria.
\end{abstract}

Keywords: Knowledge, HIV Virus, Breastfeeding

\section{Introduction}

Mother-To-Child Transmission (MTCT) is when an HIVinfected woman passes the virus to her baby. [1] This can occur during pregnancy, labour, delivery and breastfeeding. In the absence of any interventions, transmission rate ranges from $15-45 \%$ in developing countries. [1-2] The rate can be reduced to levels below $5 \%$ with effective interventions. [2] The global community has committed itself to accelerate progress for the prevention of mother-to-child transmission (PMTCT) through an initiative with the goal to eliminate new peadiatric HIV infection which had the year 2015 as its target and improve maternal newborn and child survival and health. [3]
About 1000 babies are infected with HIV on a regular basis either through pregnancy, during delivery or breastfeeding in the world with a greater percentage from those regions worst hit by the scorch of the disease. [3-4] Globally there are approximately 1.4 million pregnant women living with HIV/AIDS in low and middle income countries. [4] Only $26 \%$ of pregnant women in these countries take advantage of voluntary counseling and testing to know their HIV status. [5] Most women who are unaware of their HIV status, will equally be deficient of the knowledge about mother to child transmission and the possibility of preventing it.

Managing the knowledge about mother to child transmission of HIV will indirectly contribute in reducing the burden of HIV disease in our society. 
An intervention known as prevention of mother to child transmission (PMTC) of HIV provides drugs, counseling and psychological support to help HIV positive mothers safeguard their unborn babies and infants against the virus. [5-6] The provision of PMTCT to all women is the most effective way to end mother to child transmission but the knowledge about this among women still needs much to be desired. But far too few pregnant women and their infants have access to this preventive treatment. [7] This may not be far from the fact that many women may not be aware of the possibility of MTCT during breastfeeding, in pregnancy through the feato-placenta shunt from mother to the unborn baby and during vagina delivery. [8]

The rate of HIV sero-positivity in Nigeria is alarming because it has one of the highest prevalence rates worldwide. [7-8] As in most developing countries, vertical transmission from mother to child accounts for most of the HIV infections among Nigerian children. [8-9] Pregnant women susceptibility to HIV and its consequent transmission to the fetus provide a unique opportunity for implementing preventive strategies against HIV infections of the newborn babies.

Nigeria accounts for about $10 \%$ of all HIV cases world wide. [9] The prevalence is higher among productive young people between the ages of $20-29$ years, with $60 \%$ of new infections occurring in the 15-25 year old age group. Heterosexual transmission accounts for $80 \%$ of all infections. [9-10] In 2009, around 400,000 children aged less than 15 years became infected with HIV. [9-11] Almost all of these infections occur in low and middle socio economic countries. [12] Above $90 \%$ of cases were as a result of mother to child transmission during pregnancy, labour and delivery or breastfeeding. [9] Without interventions there is $20-45 \%$ chance that a baby born to HIV infected mother will become infected. [12-13] This poses serious danger to future generation if no drastic action is taken.

Most infant HIV infections could be averted if positive mothers have a high degree of awareness and knowledge about MTCT and the preventive strategies put in place to reduce the transmission during pregnancy and lactation. The dire need of awareness and knowledge about prevention of mother to child transmission poses a serious challenge especially among the illiterates and infected mothers in rural areas of developing countries.

Lack of adequate knowledge of mother to child transmission (MTCT) will continue to constitute a fundamental reason why mother to child transmission of HIV will be on the increase in our society. [13-14] There is therefore an urgent need to reduce (if not completely) the trend of mother to child transmission of HIV through empowering women with information on MTCT so that they can avail themselves of the available preventive strategies to reduce the spread of the disease to their children. Adequate knowledge and information about mother to child transmission of HIV will also help infected pregnant women make informed decisions on good drug compliance which will invariably reduce magnitude of HIV infection in our community. [15] It is justifiable to carry out a study of this nature that will further help contribute to the overall reduction in the scorch of HIV in Nigeria. The commitment of the global community to accelerate the progression of preventing mother to child transmission of HIV virus further justifies the reason why no stone should be left unturned into research areas that will help to achieve such goals. [16] Recognizing the potentials of what prevention of mother to child transmission could achieve, the United Nations General Assembly Special Sessions on HIV/AIDS in 2001 set targets of achieving the enhancement of prevention of mother to child transmission among member states. [17-18] Again judging from the enormity of HIV pandemic among humans especially among women, it becomes imperative that more studies on awareness about mother to child transmission will be essential as it stands to promote the use of anti-retroviral drugs among infected mothers.

\section{Mother-to-Child Transmission of HIV}

Most children less than 15 years living with HIV acquire the infection through mother-to-child transmission (MTCT) [19]. This can occur during pregnancy, labour and delivery or during breast-feeding. In the absence of interventions, the risk of such transmission is $30-45 \%$. [19-20]

The high burden of MTCT in sub-Saharan Africa (compared to the rest of the world) is due to higher rates of heterosexual transmission, higher prevalence of HIV in women of reproductive age, high total fertility rate, characteristically prolonged breastfeeding culture, as well as poor access to PMTCT interventions. [20-22]

The main aim of the study was to determine the level of awareness of mother to child transmission. (MTCT) among women in Nigeria

\section{Materials and Method}

The study design was a cross sectional survey targeted at women in Nigeria. The study location was in the six geopolitical zones of Nigeria a country in the West African sub region. Nigeria comprises 36 states and its Federal capital territory located at Abuja. Nigeria shares land border with the Republic of Benin in the west, Chad and Cameroon in the east, and Niger in the North. Its coast in the south lies on the Gulf of Guinea on the Atlantic Ocean. The three largest and most influential ethnic groups in Nigeria are the Hausa, Igbo and Yoruba.

In terms of religion Nigeria is roughly split half and half between Muslims in the North and Christians in the South; a very small minority practice traditional religion

Nigeria is the most populous country in Africa, the seventh most populous country in the world, and the most populous country in the world in which the majority of the population is black. [23] Awareness of respondents were assessed based on responses to a set of questions that bothered on the risk of possibility of HIV transmission to babies through fetoplacental shunt, breastfeeding by infected mothers.

Inclusion and exclusion criteria. All women who were not in the reproductive age group (15 to 49 years) were excluded. 
Secondary data from National Demographic and Health Survey (NDHS) carried out in Nigeria in 2008 was used. [7] The National Demographic Health Survey is one of the most comprehensive Nigerian datasets that contains extensive information on the reproductive health of women between 15 -49 years and therefore provides a unique opportunity to study the knowledge of women in the reproductive age group in the country. By using a nationally representative sample a better understanding of the knowledge of women about mother to child transmission (MTCT) of HIV epidemic in Nigeria was obtained. The NDHS survey sample was made up of 33,385 of women of reproductive age group. The data set was obtained from already analyzed results which were summarized into tables and charts using Microsoft excel.

\section{Results}

Table 1. Socio-demographic characteristics of women (respondents).

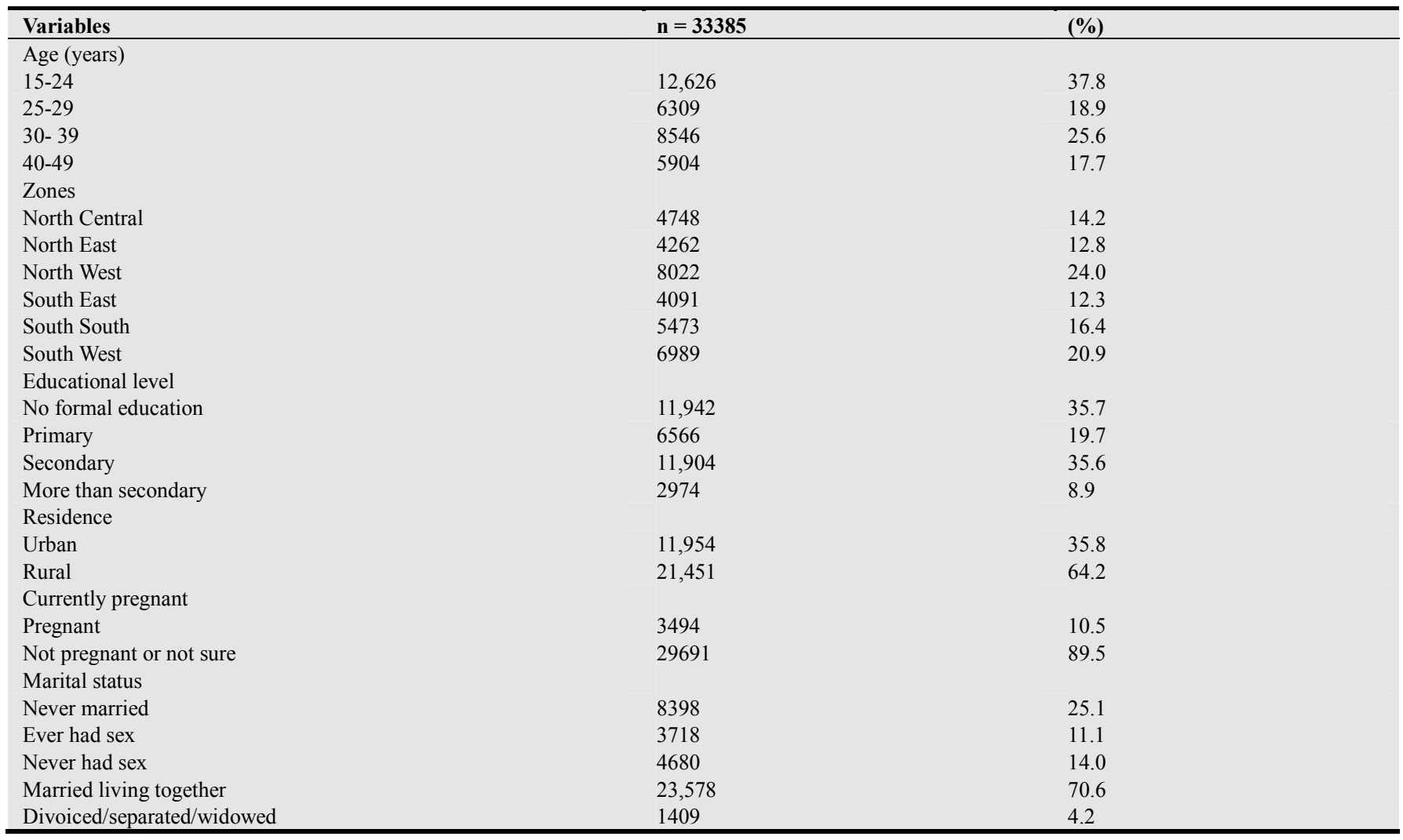

In table 1 Most of the women interviewed for the study were from the north west, (24\%). Women aged 15-24 $(27.4 \%)$ constituted the largest percentage of those interviewed for the study while women aged 45-49 constituted $12.8 \%$ were the least among the respondents.

Majority of the women (56\%) were already married and living together with their spouse. About $10.5 \%$ of the women were pregnant.

Majority (64.2\%) of those surveyed for the study lived in the rural areas of the country. Majority of the population in Nigeria live in rural areas.

About $35.7 \%$ of the women interviewed had no formal education who were in the majority among the respondents

Table 2. Level of awareness of respondents about mother to child transmission in the six geopolitical zones of nigeria.

\begin{tabular}{llll}
\hline Zones & $\begin{array}{l}\text { HIV can be transmitted } \\
\text { through breast feeding to } \\
\text { the child.\% }\end{array}$ & $\begin{array}{l}\text { Risk of MTCT can be reduced by } \\
\text { mother taking special drugs during } \\
\text { pregnancy.\% }\end{array}$ & $\begin{array}{l}\text { HIV can be transmitted by breastfeeding and risk of } \\
\text { MTCT can be reduced by mother taking special drugs } \\
\text { during pregnancy.\% }\end{array}$ \\
\hline North central & 50.1 & 30.8 & 29.1 \\
North east & 40.4 & 28.9 & 26.2 \\
North west & 33.6 & 22 & 19.1 \\
South east & 70.1 & 26.9 & 25.0 \\
South south & 58.7 & 35.2 & 32.8 \\
South west & 66.6 & 28.4 & 26.6 \\
\hline
\end{tabular}

The table above showed that a greater percentage of women $(70.1 \%)$ from southeast reported awareness about mother to child transmission through breastfeeding of infected mothers. Only 33.6\% reported awareness of MTCT from the northwest 
zone which was the least. Women from Northwest zone, $22 \%$, equally reported the least among respondents awareness about the risk that MTCT can be reduced by antiretroviral drugs.

Table 3. Awareness About MTCT Among Pregnant And Non Pregnant Women.

\begin{tabular}{llll}
\hline Currently pregnant & $\begin{array}{l}\text { HIV can be transmitted } \\
\text { by breast feeding. (\%) }\end{array}$ & $\begin{array}{l}\text { Risk of MTCT can be reduced by } \\
\text { mother taking special drugs during } \\
\text { pregnancy (\%) }\end{array}$ & $\begin{array}{l}\text { HIV can be transmitted by breastfeeding and risk of } \\
\text { MTCT can be reduced by mother taking special } \\
\text { drugs during pregnancy. (\%) }\end{array}$ \\
\hline Pregnant & 51.5 & 28.6 & 26.1 \\
Not pregnant or not sure & 52.2 & 28.2 & 25.9 \\
\hline
\end{tabular}

Multiple Responses Allowed

Awareness about MTCT among pregnant and non pregnant women. (HIV can be transmitted through breastfeeding)

From table 3 barely above half the number of pregnant women, $51.5 \%$, were aware that HIV can be transmitted by breastfeeding while $28.6 \%$ were aware that the risk of MTCT can be reduced through the use of anti retroviral drugs and $26.1 \%$ were aware that HIV can be transmitted by breastfeeding and the risk of MTCT can be reduced by taking anti-retroviral drugs.

Above average percentage of women who were not pregnant among 52.2\% showed that they were aware that HIV could be transmitted to the child during breastfeeding, while $28.2 \%$ were aware that the risk of MTCT can be reduced by mothers taking anti retro viral drugs during pregnancy. Those among the women who demonstrated knowledge of both were $25.9 \%$.

Table 4. Knowledge about MTCT by the women level of education.

\begin{tabular}{l|l|l|l|}
\hline $\begin{array}{l}\text { LEVEL OF } \\
\text { EDUCATION }\end{array}$ & $\begin{array}{l}\text { HIV can be transmitted } \\
\text { by breast feeding } \\
\text { (Percentage)\% }\end{array}$ & $\begin{array}{l}\text { Risk of MTCT can be reduced by } \\
\text { mother taking special drugs during } \\
\text { pregnancy (Percentage)\% }\end{array}$ & $\begin{array}{l}\text { HIV can be transmitted by breastfeeding and } \\
\text { risk of MTCT can be reduced by mother taking } \\
\text { special drugs during pregnancy (Percentage)\% }\end{array}$ \\
\hline No education & 29.7 & 15.2 & 13.5 \\
Primary & 56.8 & 24.9 & 22.7 \\
Secondary & 64.9 & 34.8 & 32.5 \\
\hline More than secondary & 80.5 & 61.7 & 56.8 \\
\hline
\end{tabular}

From table 4, 29.7\% of respondent with no formal education reported that HIV can be transmitted by breast feeding, while $15.2 \%$ knew that the risk of MTCT can be reduced by infected mothers taking anti-retroviral drugs. About $13.5 \%$ of the illiterates demonstrated knowledge on the possibility of transmission of HIV through breastfeeding and reduction in MTCT by positive mothers on treatment.

\section{Discussion}

The study set to assess the awareness of women in Nigeria about Mother To Child Transmission (MTCT) of HIV/AIDS. In most developing countries where HIV/AIDS is prevalent the level of awareness of MTCT contributes significantly to its increase or decrease among the people. The awareness will naturally motivate people to adopt preventive strategies such that could reduce the transmission from mother to child. Most of the women interviewed for the study were from the north west geopolitical zone (24\%). There was no even distribution of respondents of those interviewed across the six geopolitical zones. Most data on similar subjects that was conducted across the six geopolitical zones from the NDHS has the same pattern. [7] The greater percentage women respondents from the north west is in consonance with the result of the 2006 Nigerian national population census which showed the north west zone had the highest figure of population, 17,516288. [24-27] The sample size of women selected from each zone was representative enough to reflect the true opinion of the entire women population in their respective zones.

Even though the study generalized the awareness of all women about MTCT in the country, HIV positive pregnant women or lactating women should benefit much from the result of the study. The awareness of MTCT should encourage them to utilize preventive services put in place to reduce the transmission of the virus to their children.

In this study, women aged 15-24 (27.4\%) constituted the largest percentage of those interviewed. This is not too far from the fact that during this age group there is increase risking sexual activities that can favour the transmission of HIV. This is in consonance with a study done by Obdon $\mathrm{C}$ et al who reported that women between the ages of 15-24 years generally have been known to have a higher burden of HIV infections as sexual risk behavior is commoner with them. [28] Majority of women in the age group of 15-24 years were already given to marriage in most part of north geopolitical zones of the country with many exposed to multiple sexual partners that can lead to infection with HIV. Their knowledge about mother to child transmission of HIV becomes very crucial as it will enhance inform consent on the utilization of available antiretroviral drugs by positive mothers among them.

About $10.5 \%$ of the respondents were pregnant in the study which reflected the category of people classified vulnerable with respect to MTCT. This is in consonance with a study done by Abiodun M.O et al who considered a similar study among pregnant women attending ante natal clinic in the south west of the country. [29] 
Majority of those surveyed for the study lived in the rural areas of the country. From the national census population conducted in 2006 about $75 \%$ of the people live in rural areas. [27]

The study reported that most women interviewed were illiterates which created a gap in promoting awareness of MTCT among the people in the study areas. Many of them, due to illiteracy were most likely not have access to information about the subject of MTCT.

In this study $33.6 \%$ of respondents from the south west zone of the country were aware of MTCT which was the least among all the other respondents. Only 22\% reported awareness of reduction of MTCT with anti-retro viral drugs during pregnancy. This possibly explained why there was increase number of cases of HIV among women of reproductive age groups in the region as reported in previous studies conducted. [28-29].

In the study $51.5 \%$ among pregnant women were aware MTCT was possible through breastfeeding by lactating mothers, while $28.6 \%$ were aware that the risk of MTCT can be reduced through the use of anti-retroviral drugs and $26.1 \%$ were aware both HIV could be transmitted by breastfeeding and the risk of MTCT could be reduced by taking antiretroviral drugs.

This generally reflected poor awareness of MTCT among vulnerable groups of people which explained why there was an increasing rate of MTCT in some of the study areas. This is in consonance with a similar study conducted by Adeleke et al in Kano northern Nigeria who reported inadequate awareness of women on MTCT [30]

Even non pregnant women in the study did not demonstrate sufficient awareness of MTCT. About 52.2\% showed that they were aware that HIV can be transmitted to the child while breastfeeding, while $28.2 \%$ among them were aware the risk of MTCT can be reduced by mothers taking anti retro viral drugs during pregnancy. Only $25.9 \%$ were aware that MTCT can both be transmitted by breastfeeding and reduced among pregnant women who are on anti-retroviral drugs.

Only $29.7 \%$ of respondents who had no formal education were aware that HIV can be transmitted by breast feeding, while $15.2 \%$ knew that the risk of MTCT can be reduced by mother taking anti-retroviral drugs during pregnancy. About $13.5 \%$ of them were aware about the possibility of transmission of HIV through breastfeeding and reduction in MTCT by positive mothers on treatment as well.

This was in contrast with those who were educated among the respondents where a higher percentage reported awareness about MTCT. Among those with primary school level of education $56.8 \%$ knew HIV could be transmitted through breastfeeding by positive mothers while $24.9 \%$ were aware the risk of MTCT could be reduced by positive mothers taking anti-retro viral drugs while $22.7 \%$ of them demonstrated knowledge of both.

Women with secondary level of education, $64.9 \%$ were aware of transmission via breastfeeding and $34.8 \%$ demonstrated knowledge that risk of MTCT can be reduced by women taking anti-retroviral drugs while $32.5 \%$ among them have knowledge of both.

Most women with educational level above secondary school $(80.5 \%)$ demonstrated increased knowledge about the possibility of transmission of HIV during breastfeeding by positive mothers than those with lesser education. This showed the role of education in promoting awareness about MTCT. Incidentally, the illiterates (35.7\%) among the respondents were in the majority which further worsened the degree of awareness of MTCT. This calls for more concerted efforts from stakeholders to adopt more flexible communication skills to pass the message of the possibility of MTCT to these vulnerable groups

The educated among the respondents were most likely to have access to information especially with respect to MTCT than the less educated. Education plays a significant role in absorbing disseminated information around the community.

\section{Conclusion/Recommendations}

The study concluded that there was inadequate awareness about MTCT among women in Nigeria. It is therefore recommended that more effort should be geared to creating awareness among the entire geopolitical zones of Nigeria if the scorch of HIV/AIDS is to be brought below the level of public health concerns. There must also be political commitment in promoting programmes of various States Action on Control of Aids (SACA). Awareness campaign on MTCT should also be regularly disseminated at various health facility centres.

\section{References}

[1] World Health Organization publication. Antiretroviral drugs for treating pregnant women and preventing HIV infection in infants towards universal access. 2010.

[2] World Health Organization publication. Mother to child transmission of HIV. www.whoint/hiv/topics/mtct 2010. Accessed 9am May 2011.

[3] Coovadia H. Antiretroviral agents- how best to protect infants from HIV and save their mothers from AIDS. N. Engl. J. Med. 2004. 351(3); 289-292. DOI; 10.1056/NEJMe048128. PMID. 15247337.

[4] Joint United Nations programme on AIDS publication. Fact sheet. Towards universal access on HIV/AIDS. Global launch of the 2010 report.

[5] Adewole Isaac, Odutolu O, Sagay A S. Prevention of mother to child transmission of HIV in Nigeria. AIDS prevention initiative in Nigeria. 2008

[6] www.virtualhospitalmgcom/index.php?option=com. Accessed on 1oth June 2011 at $10 \mathrm{pm}$.

[7] Akinsolu A O. HIV/AIDS Scourge; Implications for Educational Planners in Nigeria. International Journal of Educational Management. (IJEM) Vol. 3. 2004.

[8] Nkwo PO. Prevention of mother to child transmission of Human Immunodeficiency Virus: The Nigerian perspective. Ann Med Health Sci Res 2012; 2: 56-65. 
[9] HIV and AIDS in Nigeria. www.avert.org/aids-nigeria. Accessed on $20^{\text {th }}$ June 2011 at $8 \mathrm{pm}$

[10] Gregson G. Mason G et al. A rural HIV epidemic in Zimbabwe. Findings from a population based survey.2001

[11] Towards the elimination of mother to child transmission of HIV in low socio economic countries. www.unicef.org/.../UNICEF WHO Elimination of MTCT of HIV. Accessed on $30^{\text {th }}$ June 2011 at $9 \mathrm{pm}$.

[12] WHO guideline for prevention of mother to child transmission. 2006.

[13] Integrated and coordinated implementations of and follow up to the outcome of major United Nations Conferences and Summits in the economic, social and related fields. $17^{\text {th }}$ September, 2010.

[14] Joint United Nations Programme on HIV/AIDS. (UNAIDS). World AIDS Day Report 2011.

[15] Webby. Aids and HIV prevalence in Nigeria. article. onlinenigeria.com/news/3360-aids-in-nigeria. $27^{\text {th }}$ September, 2011.

[16] WHO. List of indicators proportion of births occurring in rural and urban areas. National Demographic Health Survey. 2008.

[17] Joints United Nations Programme on HIV/AIDS. (UNAIDS) Report on the Global Aids Epidemic. 2010.

[18] Women, HIV and AIDS. www.avert.org/women-hiv-aids. (Accessed on $20^{\text {th }}$ August 2011 at 8pm.)

[19] Attia S. et al Sexual Transmission of HIV according to viral load and anti retroviral therapy: Systematic review and meta analysis. AIDS, 23: 1397-1404. 2009.

[20] Federal Ministry of Health. National Guideline on Prevention of Mother to Child Transmission. 2010.
[21] Antiretroviral drugs and the prevention of mother to child transmission of HIV infection in resource limited setting. Report of a technical consultation Geneva Switzerland. 2004.

[22] Tom Oguta, Abiud Omwega and Jaswant Sehmi. Infant Feeding, Alternatives for HIV Positive Mothers in Kenya. Field Exchange, Issue No 22. 2004. p26.

[23] Falola, Matthew M. et al. A history of Nigeria, Cambridge University Press, 2008.p23 ISBN 0-521.

[24] Richard M. Africa and the Americans: culture, politics, and history: a multidisciplinary encyclopedia, volume 2. ABCCLIO. 2008. P 597. ISBN 1-85109-441-5.

[25] David D. Hegemony and culture: politics and religious change among the youruba. University of Chicago Press. 1986. p111. ISBN 0-226-46790-2.

[26] Ogbonna, D. N.; Ekweozor, I. K. E.; Igwe, F. U. "Waste Management: A Tool for Environmental Protection in Nigeria". A Journal of the Human Environment 2002. 31 (1): 55-57. JSTOR 4315211.

[27] Nigerian National Population Census Figure. 2006.

[28] ObidoaCO, Cyr E. et al. Factors associated with HIV/AIDS sexual risk among women aged 15-24 years in Nigeria. African journal of public health. 2012. Vo 112.

[29] AbiodunMO. Awareness and knowledge of mother to child transmission of HIV.J.Natl Med Assoc. 2007. V99(7).

[30] SI Adeleke, M Mukhtar-Yola, GD Gwarzo. Awareness and knowledge of mothers-to child transmission of HIV among mothers attending the pediatric HIV clinic, Kano, Nigeria. Annals of African Medicine J. 2009. 8(4)210-214. 